\title{
Efeito de lâminas de irrigação no rendimento de beterraba cultivada no Alto São
}

\section{Francisco, Minas Gerais}

\section{Effect of irrigation depths on the productivity of beet cultivated in Alto São Francisco, Minas}

\section{Gerais}

\section{Efecto de las profundidades de riego sobre la productividad de la remolacha cultivada en Alto São}

\author{
Francisco, Minas Gerais
}

\section{Resumo}

Os arranjos produtivos de beterraba (Beta vulgaris L.) cultivada sob sistema de irrigação negligenciam técnicas que quantificam a real necessidade hídrica da cultura. Assim, o objetivo do trabalho foi investigar se lâminas de irrigação interferem no diâmetro e na produtividade de beterraba. O experimento foi conduzido no Instituto Federal de Minas Gerais (MG), Campus Bambuí, MG, de setembro a dezembro de 2016, com a cultivar EWTT - SK. Os tratamentos consistiram em cinco manejo de irrigação, com aplicação de lâminas de água correspondentes aos percentuais da evapotranspiração da cultura de $80 \%, 90 \%, 100 \%, 110 \%$ e $120 \%$, fornecidas manualmente toda vez que o solo atingisse $80 \%$ da sua disponibilidade real. O delineamento experimental foi em blocos casualizados, com quatro repetições. A semeadura foi feita em bandejas de isopor e as mudas transplantadas no solo aos 34 dias. A colheita foi realizada 105 dias após a semeadura. Avaliou-se o diâmetro $(\mathrm{mm})$ e a produtividade (t ha-1) de beterraba. À partir dos resultados obtidos, observou-se que houve diferença significativa para ambas avaliações, sendo que o tratamento com lâmina de $120 \%$ da evapotranspiração da cultura obteve melhor resultado nas duas avaliações, comparado aos outros tratamentos. Desta forma, conclui-se que o aumento da lâmina de irrigação apresenta efeito direto no diâmetro e na produtividade da beterraba, sendo que a lâmina de $120 \%$ da ETc apresenta os melhores resultados. O emprego de lâminas menores promovem redução nestas características analisadas, comprometendo, assim, a produção da cultura. Os resultados reforçam a importância da irrigação e do seu manejo para a produção da cultura.

Palavras-chave: Beta vulgaris; Evapotranspiração; Manejo da irrigação.

\section{Abstract}

The productive arrangements of sugar beet (Beta vulgaris L.) cultivated under irrigation systems neglect techniques that quantify the real water requirement of the crop. Thus, the objective of this work was to investigate whether irrigation depths interfere in the diameter and productivity of sugar beet. The experiment was conducted at the Federal Institute of Minas Gerais (MG), Campus Bambuí, MG, from September to December 2016, with the cultivar EWTT - 
SK. The treatments consisted of five irrigation management, with application of water depths corresponding to the percentages of crop evapotranspiration of $80 \%, 90 \%, 100 \%, 110 \%$ and $120 \%$, supplied manually whenever the soil reached $80 \%$ of its real availability. The experimental design was in randomized blocks, with four replications. Sowing was done in Styrofoam trays and the seedlings were transplanted in the soil at 34 days. Harvest was carried out 105 days after sowing. The diameter $(\mathrm{mm})$ and productivity $(\mathrm{t}$ ha-1) of beet were evaluated. From the results obtained, it was observed that there was a significant difference for both evaluations, and the treatment with a depth of $120 \%$ of the crop evapotranspiration obtained better results in both evaluations, compared to the other treatments. Thus, it is concluded that the increase in the irrigation depth has a direct effect on the diameter and productivity of beet, with the $120 \%$ ETc depth showing the best results. The use of smaller blades promotes a reduction in these analyzed characteristics, thus compromising the production of the crop. The results reinforce the importance of irrigation and its management for the production of the crop.

Keywords: Beta vulgaris; Evapotranspiration; Irrigation management.

\section{Resumen}

Los arreglos productivos de la remolacha azucarera (Beta vulgaris L.) cultivada bajo sistemas de riego descuidan las técnicas que cuantifican el requerimiento real de agua del cultivo. Así, el objetivo de este trabajo fue investigar si las profundidades de riego interfieren en el diámetro y la productividad de la remolacha azucarera. El experimento se realizó en el Instituto Federal de Minas Gerais (MG), Campus Bambuí, MG, de septiembre a diciembre de 2016, con el cultivar EWTT - SK. Los tratamientos consistieron en cinco manejos de riego, con aplicación de profundidades de agua correspondientes a los porcentajes de evapotranspiración del cultivo de $80 \%, 90 \%, 100 \%, 110 \%$ y $120 \%$, suministrados manualmente siempre que el suelo alcanzara el $80 \%$ de su disponibilidad real. El diseño experimental fue en bloques al azar, con cuatro repeticiones. La siembra se realizó en bandejas de poliestireno y las plántulas se trasplantaron al suelo a los 34 días. La cosecha se realizó 105 días después de la siembra. Se evaluó el diámetro (mm) y la productividad (t ha-1) de la remolacha azucarera. De los resultados obtenidos se observó que hubo diferencia significativa para ambas evaluaciones, y el tratamiento con una profundidad del $120 \%$ de la evapotranspiración del cultivo obtuvo mejores resultados en ambas evaluaciones, en comparación con los otros tratamientos. Así, se concluye que el aumento de la profundidad de riego tiene un efecto directo sobre el diámetro y la productividad de la remolacha azucarera, siendo el $120 \%$ de ETc el que presenta los mejores resultados. El uso de cuchillas más pequeñas promueve una reducción de estas características analizadas, comprometiendo así la producción del cultivo. Los resultados refuerzan la importancia del riego y su manejo para la producción del cultivo.

Palabras clave: Beta vulgaris; Evapotranspiración; Manejo del riego.

\section{Introdução}

A beterraba (Beta vulgaris L.) é uma hortaliça cultivada em um grande número de propriedades dos cinturões verdes brasileiros, sendo que nos últimos anos essa cultura tem se expandido para novas fronteiras agrícolas (Corrêa, et al., 2014). Consumida tanto in natura quanto cozida, a beterraba possui coloração atraente, grandes quantidades de açúcares, teores de sais minerais e vitaminas A, B1, B2 e C, sendo recomendada no tratamento de anemias e distúrbios do fígado e do baço (Gouvea, et al., 2020). Devido ao aumento da exigência dos consumidores ao se adquirir produtos hortícolas, faz-se necessário que todas as etapas do processo produtivo dessa hortaliça sejam realizadas de forma rigorosa e criteriosa, objetivando a maximização do potencial produtivo e da qualidade (Silva, et al., 2016). Assim, o manejo da irrigação pode ser utilizado para potencializar a cadeia produtiva da beterraba.

Como a água é um recurso finito e limitado, é imprescindível a adoção de uma agricultura irrigada sustável visando, além do aumento da produção e da produtividade, o uso eficiente desses recursos hídricos. Nesse contexto, o manejo correto da irrigação constitui uma etapa fundamental no desenvolvimento da maioria das culturas hortícolas. Majoritariamente, as culturas necessitam de uma determinada quantidade de água que as auxiliem a alcançar o seu potencial de produção, na qual o seu excesso ou deficiência podem causar déficits econômicos e danos ambientais relevantes (Lima, et al., 2012). Ainda, devido aos altos custos de implantação e à limitante disponibilidade de recursos hídricos, a implantação de sistemas de irrigação tornase restrita em diferentes partes do mundo, sendo fundamental conhecer as reais necessidades hídricas da cultura.

Uma das formas de determinar a quantidade de água requerida pelas plantas é por meio do cálculo da evapotranspiração da cultura (Doorenbos \& Pruitt, 1977), sendo que essas são diretamente relacionadas. A evapotranspiração da cultura (ETc) é definida pela junção da transpiração das plantas e a evaporação da água presente no solo (Sánchez \& 
Chuvieco, 2000). Sua estimativa pode ser feita conhecendo a evapotranspiração de referência (ETo), que está relacionada às condições climáticas do local da implantação, bem como, às características fisiológicas e morfológicas da espécie, representadas por meio do coeficiente da cultura (Kc) conforme proposto por Doorenbos e Pruitt, (1977).

A água constitui cerca de $90,9 \%$ da parte aérea e $87,3 \%$ do sistema radicial da beterraba; a falta desse recurso é responsável pela queda drástica de sua produção (Tivelli, et al., 2011). O período crítico à falta de umidade no solo, para a cultura, estende-se durante os primeiros 60 dias. Destaca-se que a maximização do lucro da beterraba com a produção de raízes é obtida com déficit hídrico de no máximo $25 \%$ do consumo hídrico total da planta, ou seja, lâminas abaixo de $75 \%$ da evapotranspiração da cultura não são recomendadas (Topak, et al., 2011).

Dessa forma, é importante que estudos sejam desenvolvidos para determinar lâminas de irrigação, especificamente para a cultura da beterraba, com intuito de viabilizar e difundir a exploração agrícola dessa cultura irrigada na região do alto São Francisco. Portanto, o objetivo do trabalho foi investigar se lâminas de irrigação interferem no diâmetro e na produtividade de beterraba.

\section{Material e Métodos}

A pesquisa foi desenvolvida no Laboratório de Práticas Agrícolas/Olericultura do Instituto Federal de Educação, Ciência e Tecnologia de Minas Gerais (MG), no município de Bambuí (Figura 1), com coordenadas centrais 2002’00” S e 4600’36” O, situada a 690 m de altitude. Segundo a classificação de Köppen-Geiger, o clima do local é subtropical úmido (Cwa), com inverno frio e seco e verão quente e úmido (Alvares, et al., 2013).

Figura 1. Localização e vista aérea do IFMG Campus Bambuí.
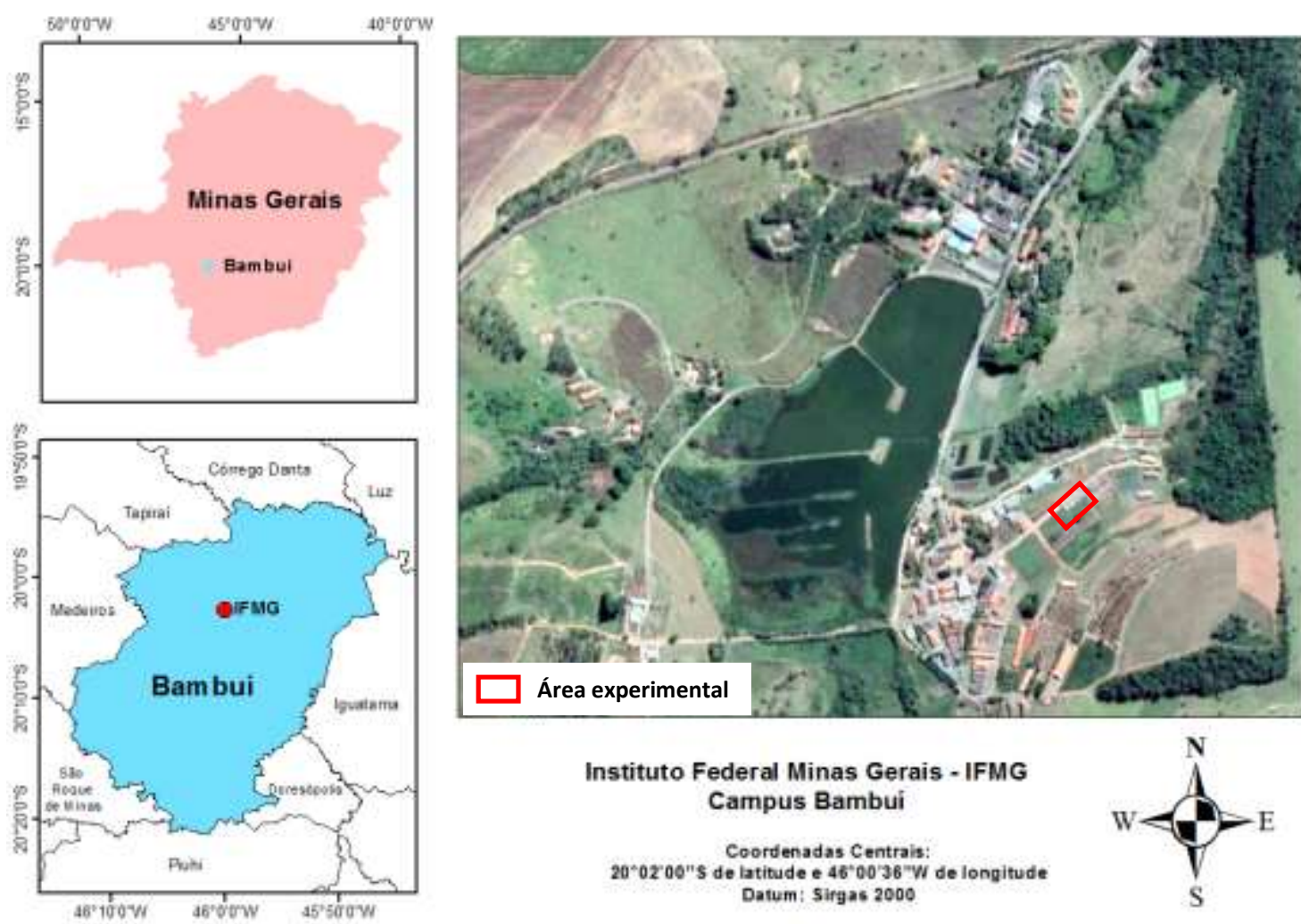

Fonte: Autores. 
A temperatura média anual de $20,8^{\circ} \mathrm{C}$, a mínima de $8,5^{\circ} \mathrm{C}$ no mês de julho, a máxima de $30,1^{\circ} \mathrm{C}$ no mês de fevereiro, com precipitação média anual é de $1465 \mathrm{~mm}$, com período chuvoso de outubro a março, que representa $85 \%$ do total precipitado durante o ano (Inmet, 2018). O estudo foi conduzido de setembro à dezembro de 2016 em ambiente protegido.

Os tratamentos estudados foram cinco lâminas de irrigação: T1) 80\% da ETc; T2) 90\% da ETc; T3) 100\% da ETc; T4) $110 \%$ da ETc; T5) $120 \%$ da ETc. O delineamento experimental usado foi de blocos casualizados, com quatro repetições, totalizando 20 parcelas, implantas em um canteiro retangular de $1 \mathrm{~m}$ de largura por $40 \mathrm{~m}$ de comprimento, totalizando $40 \mathrm{~m}^{2}$. Cada parcela foi composta de 16 plantas, quatro linhas com quatro plantas cada.

A ETc foi obtida por meio do cálculo empírico da ETo multiplicado pelo Kc. A estimativa da ETo foi feita com base da equação1 proposta por Hargreaves e Samani (1985) utilizando apenas os valores das Temperaturas máxima, mínima e média do ar e da radiação no topo da atmosfera. Os valores de Kc representam a razão entre o consumo hídrico da superfície de referência e a cultura, sendo assim, são influenciados pelo aspecto fenológico, morfológico e fisiológico da cultura, e em menor escala pelos elementos climáticos. Isto permite a utilização e transferência de valores padrões do Kc para diversas regiões geográficas e climas, constituindo, assim, a principal razão de aceitação de valores de Kc desenvolvidos em pesquisas anteriores (Allen, et al., 1998).

$$
\text { ETo- }- \text { Ra. }\left(\text { Tmáx }-T_{m i n}\right)^{\beta} \cdot(\text { Tmed }+17,8)
$$

em que: ETo é a evapotranspiração de referência $\left(\mathrm{mm}\right.$ dia $\left.^{-1}\right)$; $\alpha$ é um parâmetro empírico, sendo utilizado o seu valor original de 0,0023 ; Ra é a radiação solar no topo da atmosfera $\left(\mathrm{mm} \operatorname{dia}^{-1}\right)$; Tmáx é a temperatura máxima $\left({ }^{\circ} \mathrm{C}\right)$; Tmin é a temperatura mínima $\left({ }^{\circ} \mathrm{C}\right) ; \beta$ é um parâmetro empírico exponencial, sendo seu valor original de 0,5 e Tmed é a temperatura média $\left({ }^{\circ} \mathrm{C}\right)$. Sendo a Tmed obtida através da metodologia descrita por Allen et al. (1998), conforme equação a seguir:

$$
\underline{\text { limed }-\frac{(T \max +T \min )}{2}}
$$

O Kc referente a cultura da beterraba foi obtido a partir de dados de Doorenbos e Pruitt (1997) e Doorenbos e Kasam (1979) conforme Tabela 1.

Tabela 1. Kc em diferentes estádios de desenvolvimento, em função da umidade relativa e velocidade do vento, para a cultura da beterraba.

\section{Estádios de desenvolvimento}

\begin{tabular}{lcccc}
\cline { 2 - 5 } & I & II & III & IV \\
\hline Duração em dias de cada estádio & 25 & 35 & 28 & 12 \\
\hline Kc da Beterraba & $0,4-0,5$ & $0,7-0,8$ & $1,05-1,2$ & $0,6-0,7$ \\
\hline
\end{tabular}

Fonte: Adaptado de Doorenbos e Pruit (1977) e Doorenbos e Kasam (1979). 
O solo do ambiente de cultivo foi classificado como um Latossolo Vermelho Distrófico, de textura argilosa, conforme resultado da análise físico-hídrica (Tabela 2). O solo argiloso é considerado, por suas características, o mais favorável à retenção de água.

Tabela 2. Análise físico-hídrica do solo da área experimental, IFMG Campus Bambuí, MG

\begin{tabular}{|c|c|c|c|c|c|c|c|c|}
\hline \multirow{2}{*}{$\begin{array}{c}\text { Camada } \\
\text { (cm) }\end{array}$} & $\mathbf{C C}$ & PMP & \multirow{2}{*}{$\begin{array}{c}\text { CAD } \\
\left(\mathrm{mm} \mathrm{cm}^{-1}\right)\end{array}$} & \multirow{2}{*}{$\begin{array}{c}\text { Ds } \\
\left(\mathrm{g} \mathrm{cm}^{-3}\right)\end{array}$} & \multicolumn{3}{|c|}{ Frações Granulométricas (\%) } & \multirow{2}{*}{$\begin{array}{c}\text { Classe } \\
\text { Textural }\end{array}$} \\
\hline & \multicolumn{2}{|c|}{$\left(\mathrm{cm}^{3} \mathrm{~cm}^{-3}\right)$} & & & Areia & Silte & Argila & \\
\hline $0-10$ & 0,3947 & 0,2697 & 1,250 & & & & & \\
\hline $10-20$ & 0,3579 & 0,2474 & 1,105 & 1,47 & 13,80 & 25,90 & 60,30 & Argiloso \\
\hline $20-30$ & 0,3522 & 0,2525 & 0,997 & & & & & \\
\hline
\end{tabular}

CC - Umidade na capacidade de campo ao potencial mátrico (чm) de 0,33 atm; PMP - Ponto de murcha permanente em чm de 15 atm; CAD - Capacidade de água disponível; Ds - Densidade do solo. Fonte: Autores.

O experimento foi instalado sob sistema convencional de preparo do solo, com levantamento dos canteiros utilizando máquina operacional encanteiradora. Para recomendação da adubação foi feita a interpretação da análise química do solo (Tabela 3) com base nas recomendações para uso de corretivos e fertilizantes em MG (Ribeiro et. al, 1999). O solo apresenta características comuns de áreas com cultivo de hortaliças por longos períodos, com teores elevados de nutrientes. No plantio foi realizada a adubação com a aplicação de $100 \mathrm{~kg} \mathrm{ha}^{-1}$ de adubo formulado 04-30-16 $\left(\mathrm{N}_{-}-\mathrm{P}_{2} \mathrm{O}_{5}-\mathrm{K}_{2} \mathrm{O}\right)$ e $9 \mathrm{t}$ ha-1 de cama de frango, sendo realizado mais duas adubações durante o ciclo com $100 \mathrm{~kg} \mathrm{ha}^{-1}$ de sulfato de amônio [ $\left.\left(\mathrm{NH}_{4}\right)_{2} \mathrm{SO}_{4}\right]$.

Tabela 3. Resultado da análise química do solo da área experimental, IFMG campus Bambuí, MG, 2016

\begin{tabular}{|c|c|c|c|c|c|c|c|c|c|c|c|c|c|c|}
\hline M.O & pH & $\mathbf{C a}$ & Mg & Al & $\mathbf{H}+\mathbf{A l}$ & SB & CTC & \multirow{2}{*}{$\begin{array}{l}\mathrm{v} \\
\%\end{array}$} & $\mathbf{P}$ & $\mathbf{C u}$ & $\mathbf{F e}$ & Mn & $\mathbf{K}$ & $\mathbf{Z n}$ \\
\hline dag kg-1 & & \multicolumn{6}{|c|}{$\operatorname{cmol}_{\mathrm{c}} \mathrm{dm}^{-3}$} & & \multicolumn{6}{|c|}{$\mathrm{mg} \mathrm{dm}^{-3}$} \\
\hline 2,52 & 7,1 & 13,23 & 1,40 & 0 & 1,47 & 15,9 & 15,9 & 91,5 & 1065,4 & 8 & 21,6 & 89,5 & 500 & 16,7 \\
\hline
\end{tabular}

M.O. - matéria orgânica; SB - soma de bases trocáveis; CTC - Capacidade de troca catiônica efetiva; V - índice de saturação por bases. Fonte: Autores.

A semeadura foi realizada em bandejas de isopor, de 128 células, utilizando a cultivar EWTT - SK, comercializada pela empresa Sakata ${ }^{\circledR}$, no dia 18 de agosto de 2016. Durante as fases de germinação e crescimento das plantas elas foram irrigadas diariamente.

O transplante das mudas ocorreu 33 dias após a semeadura, em 21 de setembro de 2016, com mudas apresentando de 2 a 4 folhas e com área foliar média de $10,5 \mathrm{~cm}^{2}$. As mudas foram plantadas no espaçamento de 0,20 x $0,20 \mathrm{~m}$, totalizando 250 mil plantas por hectare (Corrêa, et al., 2014).

A colheita foi realizada 104 dias após a semeadura (71 dias após o transplante). As bordaduras foram eliminadas e foram utilizadas quatro plantas centrais para avaliação do diâmetro $(\mathrm{mm})$ e da produtividade ( $\mathrm{t}$ ha $\left.{ }^{-1}\right)$. $\mathrm{O}$ diâmetro foi medido com o auxílio de um paquímetro digital e submetido à classificação segundo a Companhia de Entrepostos e Armazéns Gerais de São Paulo (CEAGESP) e Mercado Atacadista. A tabela proposta pela CEAGESP faz a cotação de 3 tipos de beterraba: Extra AA, Extra A e Extra. O mercado atacadista utiliza 4 denominações diferentes de classificação: 3 A, 2 A, 1 A e G. Os preços da classificação $G$ não possuem equivalente na cotação de preços da CEAGESP. A indicação do melhor produto (Tabela 4) foi realizada com base nos índices de aproveitamento (IA = produto rendimento e índice de cocção), índice de 
valorização (IV = relação entre o preço de cada classificação e a classificação menos valorizada) e índice de escolha (IE $=$ razão entre o índice de aproveitamento e índice de valoração).

Tabela 4: Equivalência entre classificações Cotação da CEAGESP e Mercado Atacadista e índices para indicativo de melhor produto.

\begin{tabular}{cccccc}
\hline $\begin{array}{c}\text { Denominação Cotação } \\
\text { CEAGESP }\end{array}$ & $\begin{array}{c}\text { Denominação Mercado } \\
\text { Atacadista }\end{array}$ & $\begin{array}{c}\text { Diâmetro equatorial } \\
(\mathbf{m m})\end{array}$ & IA & IV & IE \\
\hline Extra & $1 \mathrm{~A}$ & $<50$ & 0,76 & 1 & 0,76 \\
Extra A & $2 \mathrm{~A}$ & $\geq 50 \mathrm{e}<90$ & 0,85 & 1,46 & 0,58 \\
Extra AA & $3 \mathrm{~A}$ & $\geq 90 \mathrm{e}<120$ & 0,85 & 1,95 & 0,43 \\
Não possui & $\mathrm{G}$ & $>120$ & 0,83 & 0,80 & 1,04 \\
\hline
\end{tabular}

Fonte: CEAGESP-SP (2010).

Os dados obtidos foram submetidos à análise de variância com a realização do teste $\mathrm{F}$, a $5 \%$ de probabilidade. O efeito dos tratamentos foi obtido pela análise de regressão. As análises foram efetuadas com auxílio do software Sisvar ${ }^{\circledR}$ (Ferreira, 2011).O manejo adequado da irrigação da cultura pode ser feito estabelecendo-se limites mínimos de armazenamento de água no solo para fornecer água de forma satisfatória às plantas (Vieira, et al., 2015). Esses limites podem ser estabelecidos pelo fator de disponibilidade de água no solo (f) que podem variar em uma faixa de 0,2 a 0,4 para o grupo a qual a beterraba pertence (Mantovani, et al., 2009). Nesse trabalho foi utilizado um f de 0,2 e isso significa que as plantas da beterraba podem consumir até $20 \%$ de toda a água disponível no solo. Portanto, no balanço de água no solo, a decisão de irrigar foi quando o solo estava com $80 \%$ de disponibilidade real de água. A irrigação, para o solo voltar à capacidade de campo, foi feita manualmente com o regador sobre cada parcela.

\section{Resultados e Discussão}

Durante todo o período analisado, 71 dias desde o transplante até a colheita, foram realizadas 51 irrigações e gasto uma lâmina total de 321,4 mm de água considerando o tratamento de referência (T3), caracterizado por 100\% da ETc (Figura 2). O consumo médio diário da beterraba no período estudado foi de 4,52 mm. Embora este não constitua um resultado obtido à partir dos tratamentos aplicados neste estudo, é um parâmetro importante que indica que o consumo de água pela cultura ocorreu dentro do que se esperava para a espécie. Os valores foram próximos aos obtidos no estudo realizado por Resende e Cordeiro (2007), onde foram gastos 278,5 mm de água em 65 dias de cultivo da beterraba, resultando em uma média diária de 4,28 mm. O conhecimento da evapotranspiração da cultura possibilita o uso mais eficiente da água, evitando perdas e maximizando seu aproveitamento pela cultura.

No período de execução do experimento a lâmina precipitada $(331,7 \mathrm{~mm})$ foi superior à ETc. Assim, somente a chuva poderia ter suprido a demanda hídrica da cultura. Porém, a chuva não é bem distribuída ao longo do tempo, com períodos extenso sem chuva e outros com precipitações intensas, necessitando de uma irrigação suplementar. A beterraba é muito sensível a falta de umidade no solo nos primeiros 60 dias, o que reforça a necessidade da irrigação suplementar para se alcançar produtividades ótimas (Tivelli, et al., 2011). 
Figura 2. Lâmina precipitada e ETc da cultura da beterraba no período avaliado.

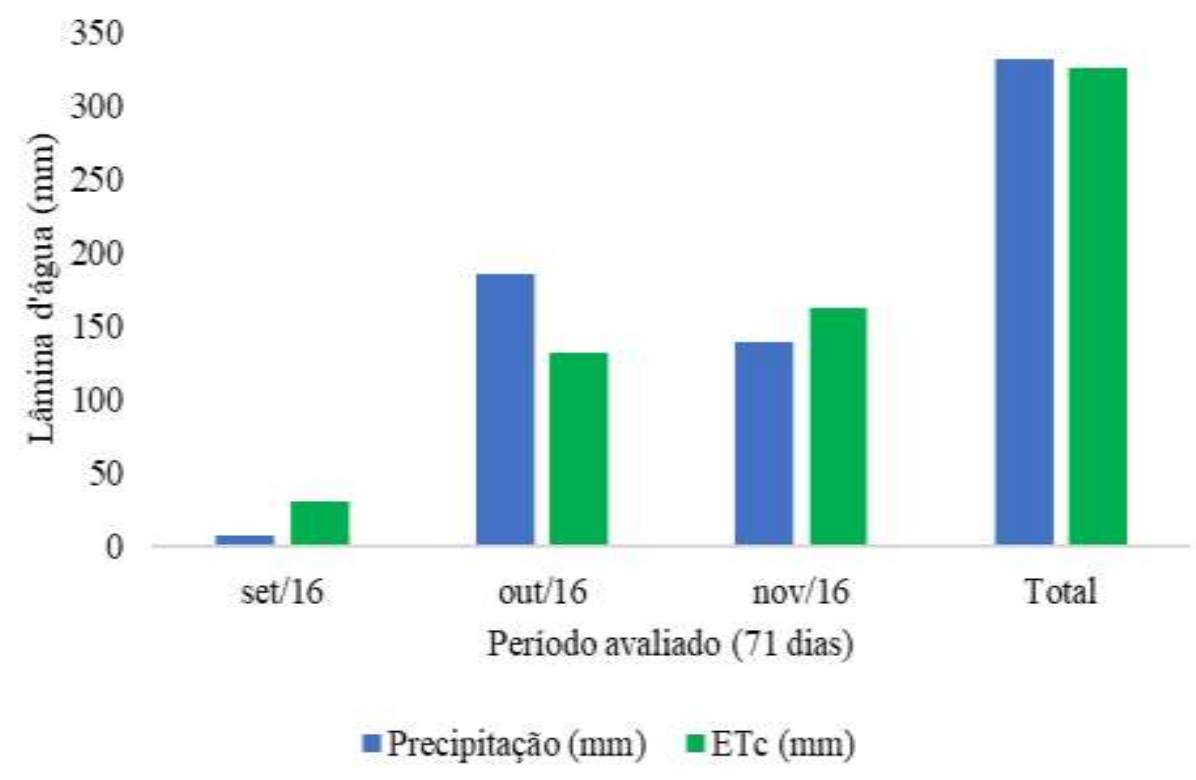

Fonte: Autores.

A irrigação influenciou positivamente o diâmetro e a produtividade de beterraba, promovendo um acréscimo de acordo com o aumento da lâmina de irrigação (Tabela 5).

Tabela 5. Valores médios da produtividade e diâmetro da beterraba submetida à diferentes lâminas de irrigação.

\begin{tabular}{cccccccc}
\hline \multirow{2}{*}{ Variáveis agronômicas } & \multicolumn{9}{c}{ Lâminas de Irrigação (\% ETc) } & & \\
\cline { 2 - 8 } & $\mathbf{8 0}$ & $\mathbf{9 0}$ & $\mathbf{1 0 0}$ & $\mathbf{1 1 0}$ & $\mathbf{1 2 0}$ & $\mathrm{R}^{2}$ \\
\hline Diâmetro $(\mathbf{m m})$ & 57,6 & 58,2 & 67,2 & 63,6 & 74,8 & $0,006 \mathrm{x}^{2}-0,836 \mathrm{x}+84,7$ & 0,81 \\
\hline Produtividade $\left(\mathbf{t ~ h a}^{-\mathbf{1}}\right)$ & 25,5 & 23 & 37,8 & 32,2 & 49,5 & $0,014 \mathrm{x}^{2}-2,171 \mathrm{x}+110,8$ & 0,78 \\
\hline
\end{tabular}

Fonte: Autores.

Houve uma tendência de aumento do diâmetro em relação ao aumento das lâminas d'água (Figura 3). O tratamento 5 (120\% ETc) obteve a maior média com $74,8 \mathrm{~mm}$ e o tratamento 1 (80\% ETc), a menor média, com 57,64 mm, apontando um percentual de $77 \%$ de aumento entre a menor e maior lâmina.

Estes resultados obtidos demonstram a importância do controle da irrigação na cultura da beterraba, bem como da aplicação das lâminas corretas, visando promover obtenção de maiores produtividades e raízes com maiores diâmetros. Os resultados também corroboram com outros trabalhos já desenvolvidos.

Conforme estudo realizado por Souza et al. (2015), o aumento da lâmina de irrigação apresenta efeito direto nas características físicas de pós-colheita da beterraba cultivar 'Wonder', proporcionando aumento significativo na produção média e diâmetro de raiz. O mesmo autor, que utilizou lâminas de 50\%, 75\%, 100\%, 125\% e 150\% da ETc, obteve a maior média de diâmetro de $57 \mathrm{~mm}$ à $150 \%$ da ETc, obtendo diferença de $85 \%$, em relação ao seu menor tratamento de 49 mm, à $75 \%$ da ETc. 
Figura 3. Diâmetro transversal de raízes de beterraba cultivar "EWTT - SK" em função de diferentes lâminas de irrigação.

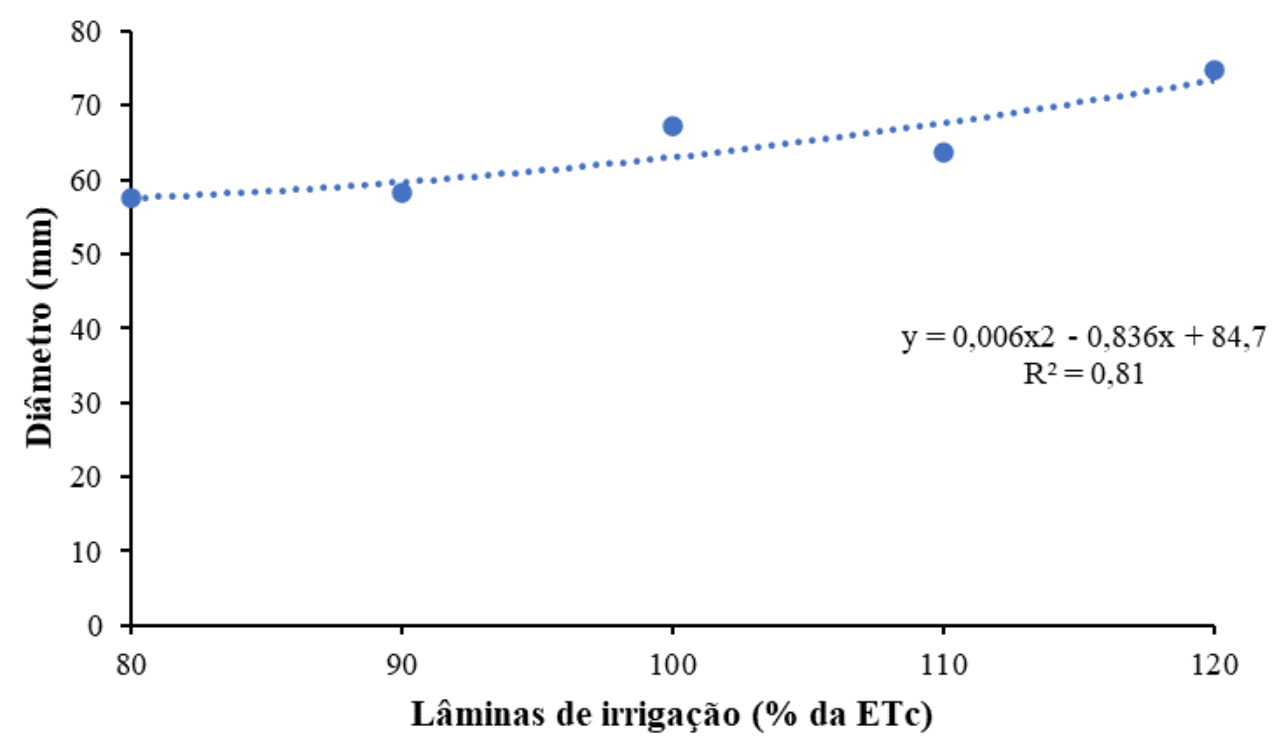

Fonte: Autores.

Resultado semelhante foi encontrado por Simões et al. (2016), ao avaliarem o desenvolvimento de cultivares de beterraba sob diferentes lâminas de irrigação, na região do Submédio do São Francisco, observaram que na medida em que as lâminas de irrigação aumentaram houve um acréscimo num modelo linear positivo para o diâmetro da raiz, sendo que para todas as cultivares a lâmina de irrigação de reposição correspondente a 150\% da ETc apresentou o maior valor de diâmetro.

Analisando as Tabelas 4 e 5, observa-se que a média do diâmetro de todos os tratamentos se encaixa na classificação, segundo a CEAGESP, Extra A. Com isso, o diâmetro equatorial das beterrabas analisadas nesse experimento se enquadra na categoria maior ou igual a $50 \mathrm{~mm}$ e menor que $90 \mathrm{~mm}$. Portanto, apresenta valores intermediários com relação às outras duas classificações (IV e IE), que condiz com custo benefício. O IA da raiz teve o mesmo valor da raiz Extra AA, considerado o melhor índice. No entanto todos os tratamentos obtiveram uma qualidade satisfatória, onde todos alcançaram um bom aproveitamento de raiz e a valorização e custo benefício intermediários, uma vez que as beterrabas de maior calibre apresentam maior valor no mercado (Ceasa Minas, 2017).

Os resultados deste trabalho indicaram também um aumento da produtividade com o aumento da lâmina d'água (Figura 4). O tratamento 5 (120\% da ETc) apresentou a maior média de produtividade, com 49,48 $\mathrm{t} \mathrm{ha}^{-1}$.

O estudo conduzido por Souza et al. (2015), demonstrou que o aumento da lâmina de irrigação apresentou efeito direto sobre a produtividade média de raiz, obtendo, para as lâminas de irrigação de 50, 75, 100, e 125 e $150 \%$ da ETc as médias de 15,5; 14,7; 19,4; 20,6 e 23,8 $\mathrm{t} \mathrm{ha}^{-1}$, respectivamente, com um percentual de $65 \%$ relacionado aos tratamentos de maior e menor média de produção, concluindo, então, haver aumento significativo na produção média de raiz. 
Figura 4. Médias da produtividade da beterraba cultivar "EWTT - SK" em função das diferentes lâminas de irrigação.

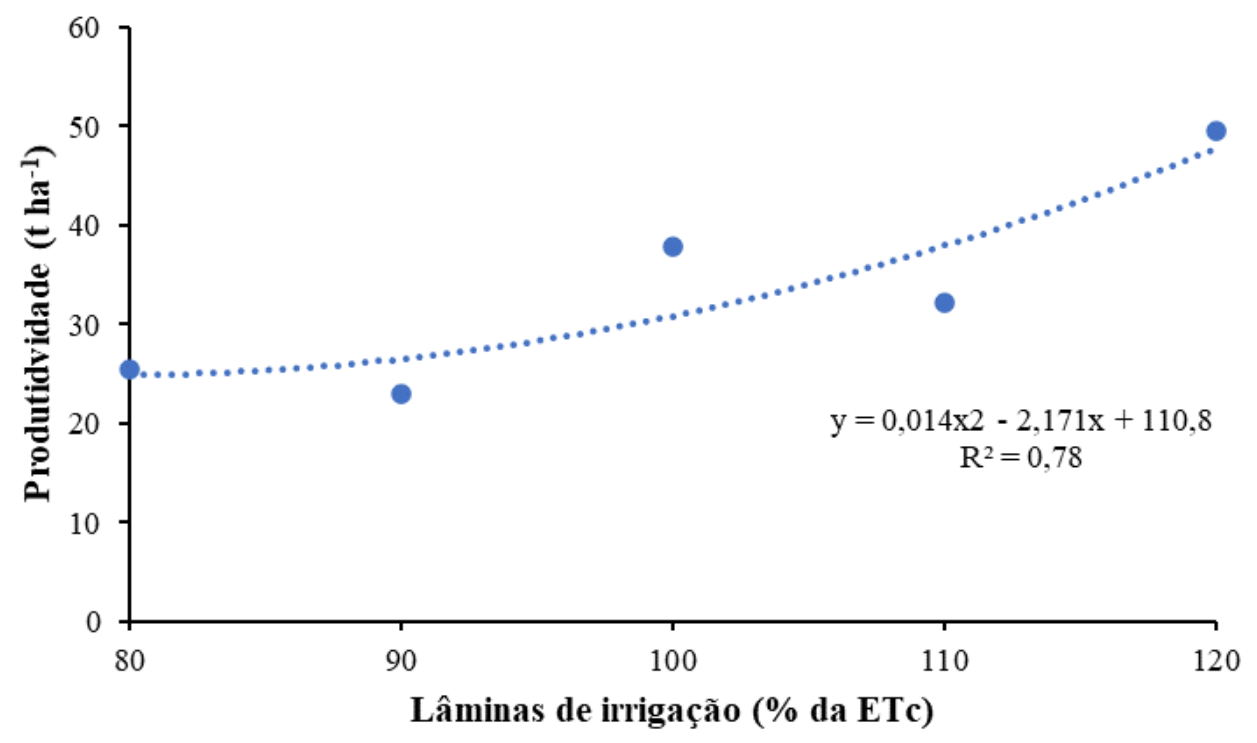

Fonte: Autores.

Essas diferenças podem ser causadas pela baixa tolerância da beterraba de mesa ao déficit hídrico, o que leva esta cultura a perdas crescentes de rendimento (Silva, et al., 2013). Para Tivelli et al. (2011), as necessidades hídricas da cultura são elevadas durante todo o ciclo produtivo, uma vez que a qualidade e a produtividade de raízes são influenciadas pelas condições de umidade do solo. Os autores afirmam ainda que a deficiência hídrica na planta de beterraba é indesejável mesmo por ocasião da colheita, pois as raízes podem ficar mais fibrosas e murchas.

A ocorrência de déficit hídrico em hortaliças compromete a produtividade e sua qualidade por causa de seu ciclo curto e do alto teor de água em sua composição. Por isso, qualquer ocorrência de estresse pode levar ao baixo rendimento e prejuízos na produção (Silva, et al., 2015).

\section{Conclusão}

O aumento da lâmina de irrigação apresenta efeito direto no diâmetro e na produtividade da beterraba da cultivar 'EWTT-SK'.

A lâmina de $120 \%$ da ETc apresenta melhor resultado no diâmetro e na produtividade da beterraba, sendo, portanto, recomendada para o cultivo.

O manejo correto da água contribui para a adoção da agricultura irrigada sustável, visando além do aumento da produção e da produtividade o uso eficiente da água. Porém, são necessários trabalhos futuros como este em diferentes regiões e para diferentes cultivares, visto que para cada região existe um genótipo mais indicado.

\section{Referências}

Allen, R. G, Pereira, L. S., Raes, D. \& Smith, M. (1998). Crop evapotranspiration - Guidelines for computing crop water requirements. Roma: FAO.

Alvares, C. A., Stape, J. L., Sentelhas, P. C., Gonçalves, J. L. D. M. \& Sparovek, G. (2013) Köppen’s climate classification map for Brazil. Meteorol. Z., 22, $711-728$.

Borghetti, J. R., Silva, W. L. C., Nocko, H. R., Loyola, L. N. \& Chianca G. K. (2017). Agricultura Irrigada Sustentável no Brasil: Identificação de Áreas Prioritárias. Brasília: FAO. 
CEAGESP. (2010). Companhia de Entreposto e Armazéns Gerais de São Paulo. Ficha técnica para classificação da beterraba (Beta vulgaris L.). http://www.ceagesp.gov.br/hortiescolha/anexos/ficha_beterraba.pdf.

Ceasa Minas. (2010). Centrais de Abastecimento de Minas Gerais S/A. Preços médios pagos pelo consumidor em BH/MG: Comparativo de menores preços. http://www.ceasaminas.com.br/informacoes_mercado.asp.

Corrêa, C. V., Cardoso, A. I., Souza, L. G., Antunes, W. L., \& Magolbo, L. A. (2014). Produção de beterraba em função do espaçamento. Horticultura Brasileira, 32 (1), 111-114.

Doorenbos, J. \& Kassam, A. H. (1979). Efeito da água no rendimento das culturas. Trad. De H.R. Gheyi, A.A. de Sousa, F.A.V. Damasceno E J.F. de Medeiros. Campina Grande: UFPB.

Doorenbos, J. \& Pruitt, W. O. (1977) Guidelines for predicting crop water requirements. Roma: FAO.

Ferreira, D. F. Sisvar: a computer statistical analysis system. Ciência e Agrotecnologia, 35, 1039-1042, 2011.

Gouvea, I. F. S., Maciel, M. P. R., Carvalho, E. E. N., Boas, B. M. V., \& Nachtigall, A. M. (2020). Caracterização física e química de farinha de talo de beterraba. Brazilian Journal of Development, 6 (3), 15814-15823.

Hargreaves, G. H. \& Samani, Z.A. (1985). Reference crop evapotranspiration from temperature. Appl. Engreg. Agric., 1 (2), 96-99.

INMET (2018). Normais Climatológicas do Brasil 1981 - 2010. Brasília, DF: Instituto Nacional de Meteorologia

Lima, M. E. D., Carvalho, D. F. D., Souza, A. P. D., \& Rocha, H. S. (2012). Desempenho do cultivo da berinjela em plantio direto submetida a diferentes lâminas de irrigação. Revista Brasileira de Engenharia Agrícola e Ambiental, 16 (6), 604-610.

Mantovani, E. C., Bernardo, S. \& Palaretti, L. F. (2009). Irrigação: princípios e métodos (3a ed.). Viçosa: UFV.

Resende, G. M \& Cordeiro, G. G. (2007). Uso da Água Salina e Condicionador de Solo na Produtividade de Beterraba e Cenoura no Semi-Árido do Submédio São Francisco. Comunicado Técnico 128, Embrapa, Petrolina - PE.

Ribeiro, A. C., Guimarães, P. T. G. \& Alvarez V. H. V., eds. (1999). Recomendações para uso de corretivos e fertilizantes em Minas Gerais. $5^{a}$ Aproximação. Viçosa, MG, Comissão de Fertilidade do Solo do Estado de Minas Gerais - CFSEMG.

Sánchez, M. \& Chuvieco, E. (2000). Estimación de evapotranspiración del cultivo de referencia, ETo, a partir de imágenes NOAA-AVHRR. Revista de Teledetección, 14 (1), 1 - 10.

Silva, A. O., Silva, E. F. F. \& Klar, A. E. (2013). Eficiência de uso da água em cultivares de beterraba submetidas a diferentes tensões de água no solo. Water Resources and Irrigation Management, 2 (1), 27-36.

Silva, A. O, Silva E. F. F, Bassoi L. H. \& Klar A. E. (2015). Desenvolvimento de cultivares de beterraba sob diferentes tensões de água no solo. Horticultura Brasileira, 33(1), $12-18$.

Silva, P. N. L, Lanna, N. B. L., \& Cardoso, A. I. I. (2016). Produção de beterraba em função de doses de torta de mamona em cobertura. Horticultura Brasileira, 34 (3), $416-421$.

Simões, W. L., de Souza, M. A., Yuri, J. E., Guimarães, M. M. \& Gomes, V. H. F. (2016). Desempenho de cultivares de beterrabas submetidas a diferentes lâminas de irrigação no Submédio São Francisco. Water Resources and Irrigation Management, 5 (2), 51-57.

Souza, M. A., Simões, W. L.; Yuri, J. E., Guimarães, M. J. M., Santos, J. E. \& Araujo, E. F. J. (2015) Características físicas da pós-colheita da beterraba em função de cinco lâminas de irrigação. In: XXV CONIRD - Congresso Nacional de Irrigação e Drenagem, UFS - São Cristóvão/SE, p. 869-873, 2015.

Tivelli, S. W., Factor, T. L., Teramoto, J. R. S., Fabri, E. G., Moraes, A. D., Trani, P. E., \& May, A. (2011). Beterraba: do plantio à comercialização. Campinas: Instituto Agronômico.

Topak, R., Süheri, S., \& Acar, B. (2011). Effect of different drip irrigation regimes on sugar beet (Beta vulgaris L.) yield, quality and water use efficiency in Middle Anatolian, Turkey. Irrigation Science, 29 (1), 79 - 89.

Vieira, G. H. S., Mantovani, E. C., Sediyama, G. C.; Monaco, P. A. V. (2015). Lâminas de irrigação em cana-de-açúcar para diferentes condições de disponibilidade hídrica. Irriga, v. 1 (2), 137 - 148. 